\title{
Dynamic Response Characteristics of Aeolian Sediment along Sichuan- Tibet Railway
}

\author{
Kan Han*, Chunxiao Xue \\ Northwest Research Institute Co., Ltd. of China Railway Engineering Corporation, Lanzhou 730000, Gansu, China \\ Email:522085779@qq.com
}

\begin{abstract}
In order to reduce the damage of liquefaction of aeolian sand along the Sichuan-Tibet railway, the dynamic response characteristics of saturated aeolian sand in the study area were discussed by using shaking table test. The results show that the macroscopic characteristics of saturated aeolian sand in the study area are subsidence, water flow and fracture. The displacement time history shows that the surface displacement increases with increasing the input ground motion acceleration. When the acceleration is small $(0.1 \mathrm{~g})$, the vibration in the soil layer has an obvious tendency to enlarge continuously from bottom to top. With the increase of the acceleration $(0.2 \mathrm{~g})$, the amplification trend basically disappeared. When the acceleration increases to $0.3 \mathrm{~g}$, the ground motion increases first and then decreases.

Keywords: Sichuan-Tibet railway, dynamic response characteristics, aeolian sediment, liquefaction
\end{abstract}

\section{Introduction}

The Sichuan-Tibet Railway is a high-speed railway connecting Sichuan Province and Tibet Autonomous Region in China. It is the second railway into Tibet and one of the trunk railways in southwest China. The Sichuan-Tibet railway runs from Chengdu in Sichuan province in the east to Lhasa in the west, with a total length of 1,838 $\mathrm{km}$ and a designed speed of 160 to $200 \mathrm{~km} / \mathrm{h}$. Wind-blown sand sections are widely distributed along the Sichuan-Tibet Railway, accounting for more than $10 \%$ of the total length of the railway. The areas along the railway route are characterized by complex terrain, large height difference, variable wind direction and strong valley wind action. Therefore, the problem of aeolian sand liquefaction in high intensity areas is very complicated for roadbed engineering.

In the past few decades, remarkable achievements have been made in the research of sand liquefaction at home and abroad, which can provide technical reference for the treatment of sand liquefaction foundation. However, the above research results are based on the characteristics of liquefied sand in general areas, and there are few studies on the liquefaction of aeolian sand in high intensity areas. The aeolian sand along the Sichuan-Tibet railway is characterized by fine soil particles, thick overburden layer and high saturation. It is of great guiding significance to study the liquefaction characteristics of aeolian sand in this region. In this paper, the dynamic response characteristics of aeolian sand in the study area are discussed by analyzing the macroscopic characteristics of aeolian sand liquefaction, displacement time history and acceleration time history.

\section{Shaking table testing}

\subsection{Testing system}

The size of the shaking table for this test is $1.2 \mathrm{~m} \times 0.4 \mathrm{~m}$, with a power amplifier of $15 \mathrm{kVA}$ rated output power, a maximum load of $200 \mathrm{~kg}$, a maximum acceleration of $980 \mathrm{~m} / \mathrm{s} 2$, and a maximum speed of $2 \mathrm{~m} / \mathrm{s}$. The allowable eccentric torque of the system is $290 \mathrm{kN} \cdot \mathrm{m}$, and the horizontal vibration frequency is $2-100 \mathrm{~Hz}$.

\subsection{Model boxes}

Rigid model boxes were used in this model test, with dimensions of $100 \mathrm{~cm}$ long, $40 \mathrm{~cm}$ wide and $80 \mathrm{~cm}$ high. Among them, in order to reduce the influence of the side wall of the model box on the test, three sides of the model box are built with $10 \mathrm{~cm}$ plastic foam board, and the remaining one side is set with transparent glass to observe the liquefaction phenomenon of sand during the vibration process.

\subsection{Sensors}

Generally, the surface displacement of soil is the largest in the process of vibration, so three displacement sensor along the length direction model box is designed to monitor the displacement change characteristics of topsoil, displacement 
meter setting near the foam board, and laid in the center of the model no. 3, displacement, displacement of $2 \mathrm{~m}$ setting in the middle of the No. 1 and No. 3, the distance between the three displacement sensors about $20 \mathrm{~cm}$. Among them, No. 1 displacement meter is arranged near the foam plate, No. 3 displacement meter is arranged at the center of the model, and No. 2 displacement meter is arranged between No. 1 and No. 3. The distance between the three displacement meters is about $20 \mathrm{~cm}$. To monitor the pore water pressure at different depths, five pore water pressure sensors were placed along the depth, with a distance of about $15 \mathrm{~cm}$ between them. In order to understand the change law of acceleration in depth direction and horizontal direction, an acceleration sensor is arranged every $15 \mathrm{~cm}$ along the depth direction, and three acceleration sensors are set $40 \mathrm{~cm}$ away from the bottom of the model box, and the horizontal distance is about $15 \mathrm{~cm}$.

\section{Result analysis}

\subsection{Macro phenomenon}

Figure 2 shows the macroscopic phenomena on liquefaction of sand before vibration (Figure 1a), after vibration of $0.1 \mathrm{~g}$ sine wave (Figure $1 \mathrm{~b}$ ), after vibration of $0.2 \mathrm{~g}$ sine wave (Figure 1c) and after vibration of $0.3 \mathrm{~g}$ sine wave (Figure $1 \mathrm{~d}$ ). The following details can be observed:

(1) After the input of $0.1 \mathrm{~g}$ sine wave, the model showed no significant change (Figure $1 \mathrm{~b}$ ), but the model infiltration line increased by about $14 \mathrm{~cm}$.

(2) After the input of $0.2 \mathrm{~g}$ sine wave, subsidence occurred on the surface of the model, and cracks began to appear in the middle of the model. The soil at the edge rapidly subsided, and water gradually overflowed from the edge. The infiltration line in the middle of the model rose about $23 \mathrm{~cm}$.

(3) After the input of $0.3 \mathrm{~g}$ sine wave, the crack continues to extend and overflow a large amount of water. At this time, the soil surface settlement is about $10 \mathrm{~cm}$, and the liquid level has exceeded the soil surface.

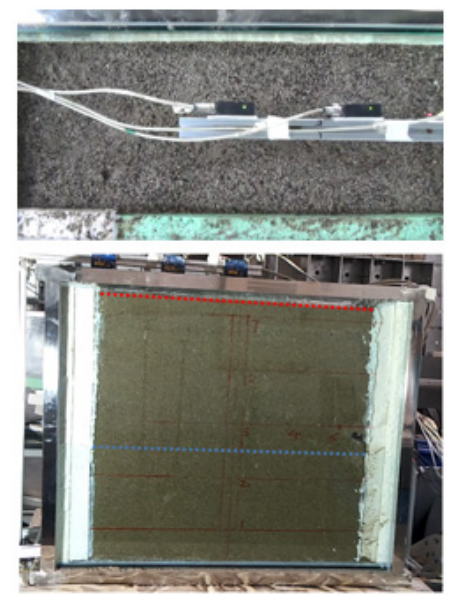

(a) Before vibration

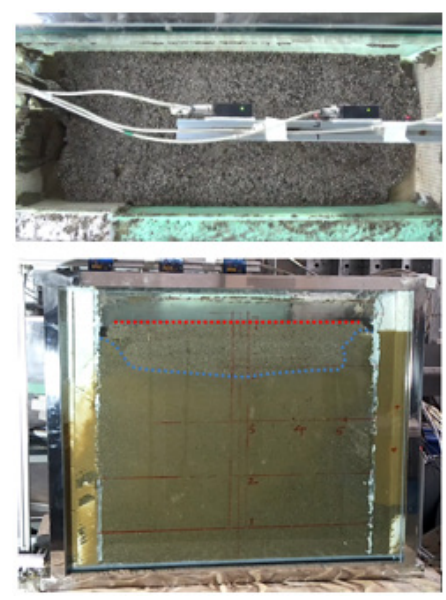

(c) After $0.2 \mathrm{~g}$ vibration

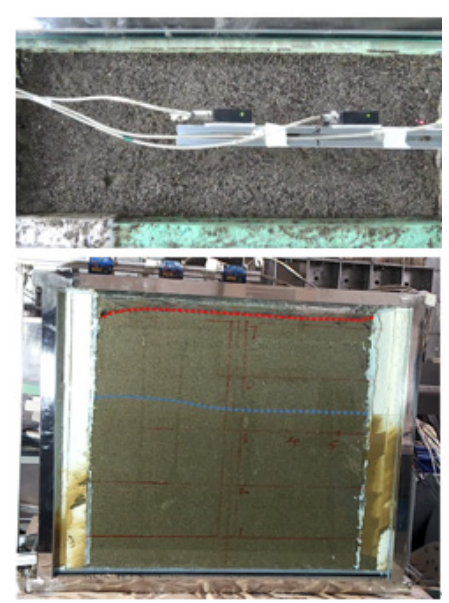

(b) After $0.1 \mathrm{~g}$ vibration
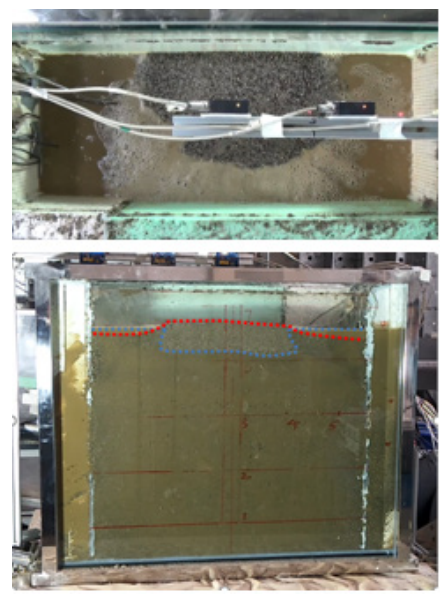

(d) After 0.3 g vibration

Figure 1. The macroscopic phenomena on liquefaction of sand 


\subsection{Displacement time history}

Figure 2 shows the settlement history curves of different monitoring points in the sand under the action of vibration. It can be observed that the closer to the edge of the model box, the smaller the settlement of the topsoil is, indicating that the boundary layer has a certain inhibitory effect on the settlement, which is mainly caused by the boundary effect. In addition, it can be seen from the figure that the ground subsidence changes step by step with time. After the acceleration of ground motion peak with each change, the ground subsidence increases sharply first and then gradually converges to a certain value. The larger the peak of ground motion acceleration is, the greater the convergence value is. This indicates that the stronger the ground motion is, the greater the energy input to the soil is, the stronger the ground motion response of the soil is, and the greater the corresponding surface settlement is.

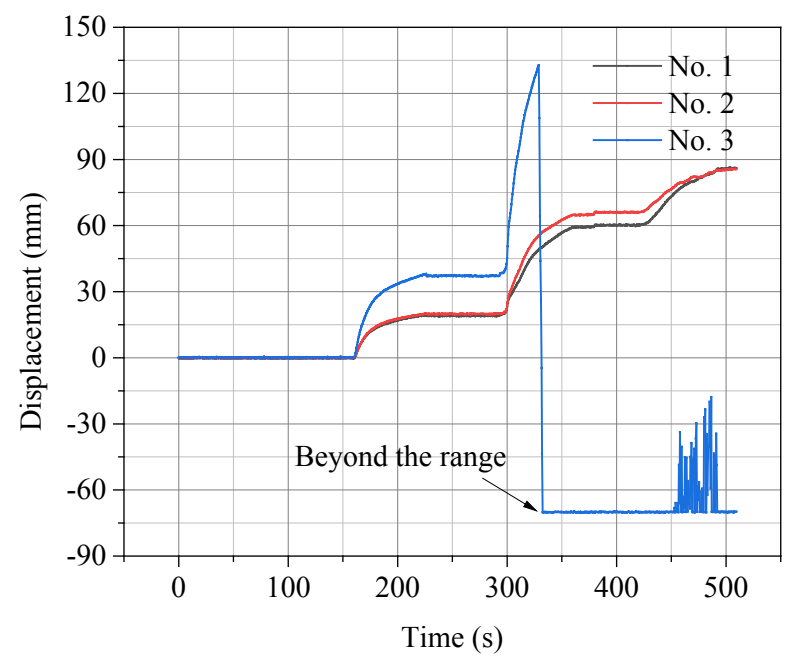

Figure 2. Settlement history curves of different monitoring points

\subsection{Acceleration time history}

Figure 3 shows the time-history curve of acceleration at different monitoring points in sand under vibration. In the shaking table test, the model should be able to accurately simulate the seismic response of the semi-infinite foundation in the actual site, and the horizontal shear deformation of the soil must be guaranteed by the model box. It can be seen from the acceleration time history curves of No.3 and No.5 that the shape of the acceleration time history curve wave at each measuring point is basically the same, and the peak acceleration is also similar, indicating that the side wall of the model box more or less has boundary effect. However, the monitoring points can be arranged in the center of the model to reduce its effect, so as to meet the requirements of this shaking table test. From the time history curves of No.1, No. 2, No. 3, No. 6 and No. 7 , it can be found that when $0.1 \mathrm{~g}$ sinusoidal wave is input, the ground motion in the soil layer has a relatively obvious trend of continuous amplification from bottom to top. When $0.2 \mathrm{~g}$ sine wave is input, the ground motion in the soil layer has no obvious amplification or reduction, the main reason is that after $0.1 \mathrm{~g}$ sine wave, the sand is vibration-dense, and the ground motion in the soil layer is similar to that in the rigid body. When $0.3 \mathrm{~g}$ sine wave is input, the ground motion in the soil layer increases first and then decreases from bottom to bottom. The possible reason is that the sand is liquefied at this time.

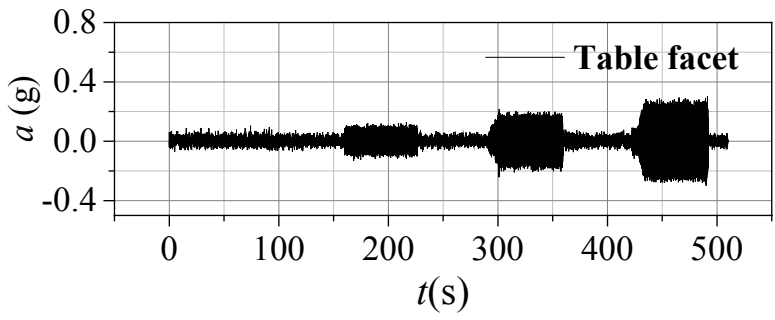



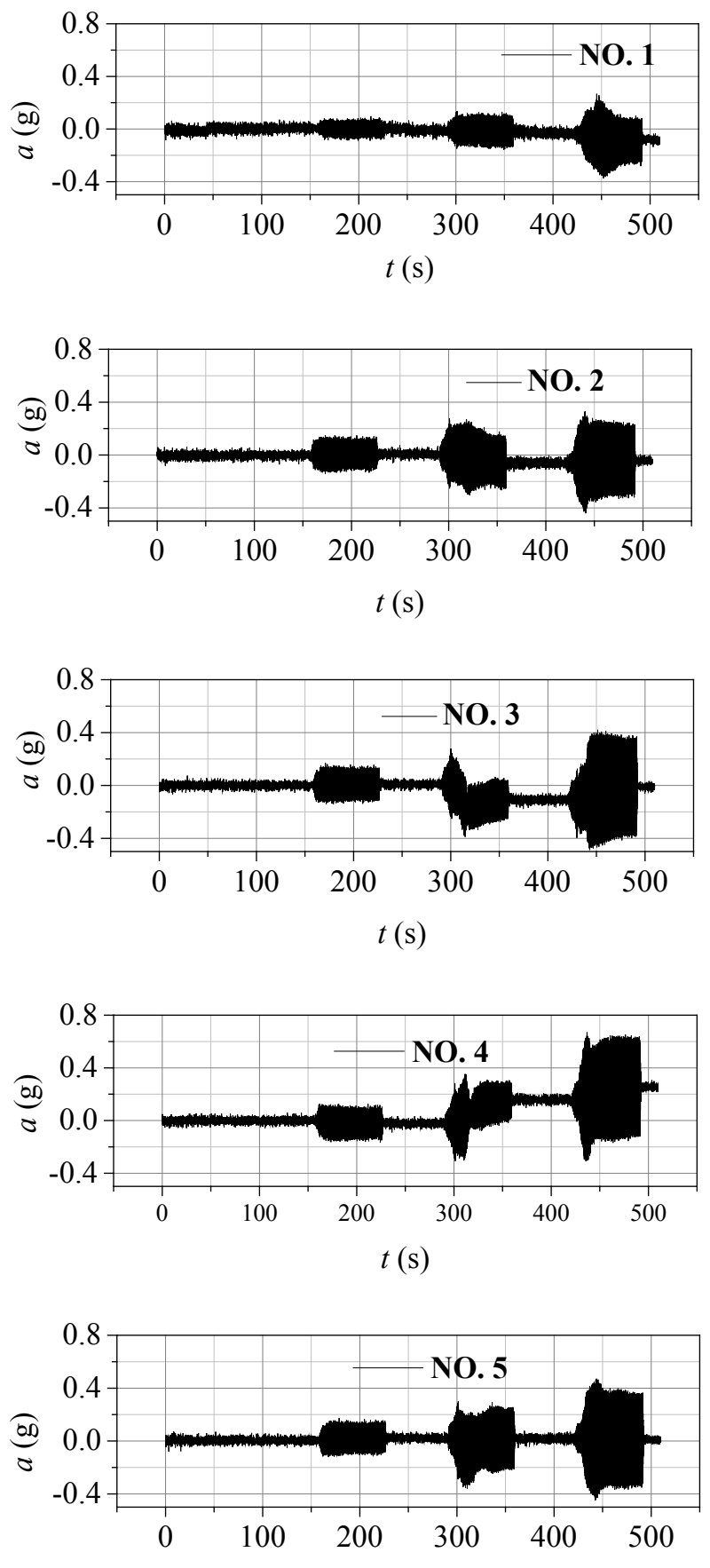

$t(\mathrm{~s})$

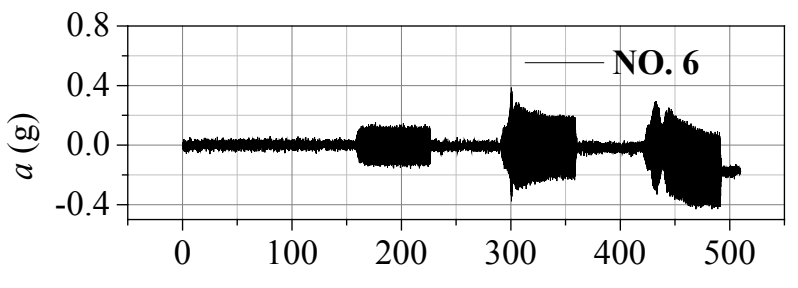

$t(\mathrm{~s})$ 


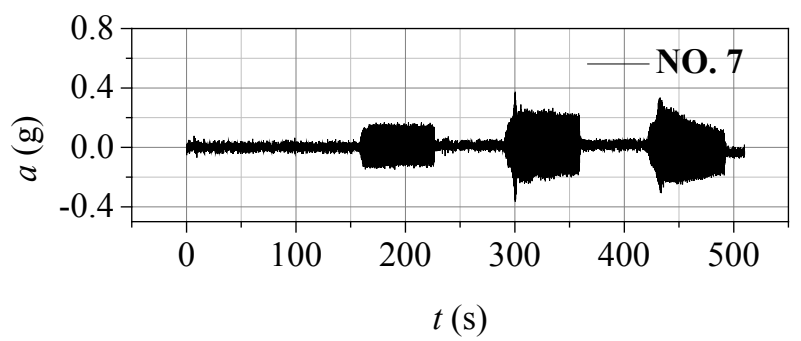

Figure 3. Acceleration history curves of different monitoring points

\section{Conclusions}

(1) The macroscopic characteristics of saturated aeolian sand in the study area are subsidence, water flow and fracture, and the seismic response strength of sand increases with the increase of acceleration.

(2) The closer to the center of the model box, the greater the settlement of the topsoil is, indicating that the boundary effect exists in the model box. The monitoring points can be arranged in the center of the model to reduce this effect. Moreover, the displacement time history shows that the surface displacement increases with increasing the input ground motion acceleration.

(3) When the acceleration is small, the vibration in the soil layer has an obvious tendency to enlarge continuously from bottom to top. With the increase of the acceleration $(0.2 \mathrm{~g})$, the amplification trend basically disappeared. When the acceleration increases to $0.3 \mathrm{~g}$, the ground motion increases first and then decreases.

\section{References}

[1] XU Z X, ZHANG L G, JIANG L W, et al. Engineering Geological Environment and Main Engineering Geological Problems of Ya'an-Linzhi Section of the Sichuan-Tibet Railway[J]. Advanced Engineering Science. 2021; 53(3): 29-42.

[2] ZHENG D M. Research on the Design Parameters of Aeolian Sand Control Engineering in La - Lin Section of Sichuan-Tibet Railway[J]. Journal of Railway Engineering of Society Engineering Science. 2020; 266(11): 15-18.

[3] MARTIN G R, FINN W D L, SEED H B. Fundamentals of liquefaction under cyclic loading[J]. Journal of the Geotechnical Engineering Division. 1975; 101(5): 423-438.

[4] HE J P, CHEN W Z. Numerical simulation experiment of typical liquefaction characteristics for free field[J]. Earthquake Engineering and Engineering Vibration. 2011; 31(2): 162-169.

[5] LU X L, REN H M, LI P Z, et al. Numerical analysis of free field system in liquefiable site and validation of shaking table tests[J]. Chinese Journal of Rock Mechanics and Engineering. 2009; 28(Supp.2): 4046-4053.

[6] HE J P, CHEN W Z. Numerical simulation experiment of typical liquefaction characteristics for free field[J]. Earthquake Engineering and Engineering Vibration. 2011; 31(2): 162-169. 